\title{
RESEARCH
}

Open Access

\section{Socioeconomic disparities in abdominal obesity over the life course in China}

\author{
Panpan Zhao ${ }^{\dagger}$, Xiaoli Gu ${ }^{\dagger}$, Dongfu Qian*, Fan Yang ${ }^{*}$ and for the Healthy Aging and Development Study \\ Group in Nanjing Medical University, and for the Data Mining Group of Biomedical Big Data in Nanjing \\ Medical University
}

\begin{abstract}
Background: Abdominal obesity has become an important public health issue in China. Socioeconomic disparities are thought to be closely related to the prevalence of abdominal obesity. Exploring socioeconomic disparities in abdominal obesity over the life course in China could inform the design of new interventions to prevent and control abdominal obesity.
\end{abstract}

Methods: The China Health and Nutrition Survey (CHNS) was a prospective household-based study involving seven rounds of surveys between 1993 and 2011. Twenty three thousand, two hundred and forty-three individuals were followed up over an 18-year period. The mixed effects models with random intercepts were used to assess the effects on abdominal obesity. Six key socioeconomic indicators, with age and age-squared added to the models, were used to identify socioeconomic disparities in abdominal obesity over the adult life course.

Results: Prevalence of abdominal obesity increased non-linearly with age over the adult life course. Abdominal obesity was more prevalent in younger than older birth cohorts. Positive period effects on the prevalence of abdominal obesity were substantial from 1993 to 2011, and were stronger among males than females. Prevalence of abdominal obesity was higher among ethnic Han Chinese and among the married [coefficient (95\% confidence intervals): $0.03(0.003,0.057)$ and $0.035(0.022,0.047)$, respectively], and was lower among males [coefficient ( $95 \%$ confidence intervals): $-0.065(-0.075,-0.055)$ ]. A higher-level of urbanization and higher household income increased the probability of abdominal obesity [coefficient (95\% confidence intervals): $0.160(0.130,0.191), 3.47 \mathrm{E}^{-4}$ $\left(2.23 \mathrm{E}^{-4}, 4.70 \mathrm{E}^{-4}\right)$, respectively], while individuals with more education were less likely to experience abdominal obesity [coefficient (95\% confidence intervals): $-0.222(-0.289,-0.155)$ ] across adulthood.

Conclusions: In China, abdominal obesity increased substantially in more recent cohorts. And people with lower educational attainment, with higher household income, or living in more urbanized communities may be the disadvantaged population of abdominal obesity over the adult life course. Effective interventions targeting the vulnerable population need to be developed.

Keywords: Abdominal obesity, China, Life course, Socioeconomic disparities

\footnotetext{
*Correspondence: dongfu016@126.com; youngfan@njmu.edu.cn

†Panpan Zhao and Xiaoli Gu contributed equally to this work.

School of Health Policy \& Management, Nanjing Medical University, 101

Longmian Avenue, Jianging Districe, Nanjing 211166, Jiangsu Province,

People's Republic of China
}

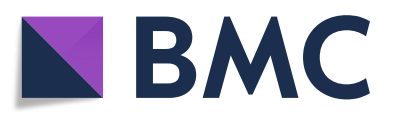

(C) The Author(s). 2018 Open Access This article is distributed under the terms of the Creative Commons Attribution 4.0 International License (http://creativecommons.org/licenses/by/4.0/), which permits unrestricted use, distribution, and reproduction in any medium, provided you give appropriate credit to the original author(s) and the source, provide a link to the Creative Commons license, and indicate if changes were made. The Creative Commons Public Domain Dedication waiver (http://creativecommons.org/publicdomain/zero/1.0/) applies to the data made available in this article, unless otherwise stated. 


\section{Background}

Abdominal obesity has become an important public health issue in China [1]. With rapid changes in social and economic conditions, as well as dietary patterns, China has been experiencing a substantial increase in the prevalence of abdominal obesity [1]. Abdominal obesity increases risks of diabetes, metabolic syndrome [2], cardiovascular disease and mortality [3, 4]. Socioeconomic disparities are thought to be closely related to the distribution of abdominal obesity [5, 6], abdominal obesity may tend to be more prevalent among the adult population with low socioeconomic status. Exploring socioeconomic disparities in abdominal obesity could inform the design of new interventions to prevent and control abdominal obesity.

Although some studies based on cross-sectional surveys have examined socioeconomic disparities in abdominal obesity $[7,8]$, they could not observe the long-term changes of the variables because some socioeconomic determinants are likely to change with age and period $[9,10]$. Those cross-sectional studies also lack the ability to examine cohort effects on abdominal obesity and disentangle the effects of lifespan [11] in socioeconomic disparities of abdominal obesity. So, longitudinal studies with multiple birth cohorts are needed to represent a longitudinal trend of abdominal obesity and more precisely identify such socioeconomic disparities in abdominal obesity over the adult life course. To date, longitudinal research on abdominal obesity and its socioeconomic factors with a large representative sample does not exist in China. Furthermore, waist-to-height ratio (WHtR) is regarded as a superior indicator of abdominal obesity [12], and has been shown to be a better predictor of metabolic syndrome [2], adverse cardiovascular events and mortality [3] than waist circumference (WC) or body mass index (BMI) in the general population [13, 14]. In studies that use WHtR as an indicator, abdominal obesity is generally defined as WHtR of over $0.5[12,13]$.

Data from the China Health and Nutrition Survey (CHNS) with a large population-based cohort over an 18-year period were used to assess age-period-cohort effects on abdominal obesity, based on WHtR cutoffs, to identify socioeconomic disparities in abdominal obesity over the adult life course.

\section{Methods}

\section{Data sources}

We used longitudinal data from the CHNS of1993, 1997, 2000, 2004, 2006, 2009, and 2011 [10, 15-17] for our analysis. The survey protocols and process for obtaining informed consent were approved by the institutional review committees of the University of North Carolina at Chapel Hill, National Institute of Nutrition and Food Safety, Chinese Center for Disease Control and Prevention, China-Japan
Friendship Hospital, and Ministry of Health. The CHNS covered approximately $56 \%$ of China's population across nine diverse provinces (Heilongjiang, Liaoning, Guangxi, Guizhou, Hubei, Hunan, Henan, Jiangsu, and Shandong). A multistage, random cluster sampling process [10] was used to draw a sample in each of the provinces. Counties and cities in each province were stratified by income (low, middle and high) and a weighted sampling scheme was used to randomly select four counties and two cities in each province. Villages and townships within the counties, and urban and suburban neighborhoods within the cities were selected randomly. In each community, 20 households were randomly selected and all household members were interviewed. The CHNS followed up the originally sampled households and new households formed from previous households by the household roster. Additional details about sampling methods, response rates, and data quality are reported elsewhere [17].

Data was collected at the local clinic or participants' homes by well-trained health workers. Height was measured to the nearest $0.1 \mathrm{~cm}$ using SECA 206 wall-mounted metal tapes according to a standard protocol [18]. Waist circumference (WC) was measured to the nearest $0.1 \mathrm{~cm}$ using a Seca tape measure (Seca North America, Chino, CA, USA) at the midpoint between the lowest rib margin and the iliac crest. Participants were asked to remove bulky clothing and shoes. WHtR is defined as their WC $(\mathrm{cm})$ divided by height $(\mathrm{cm})$. Abdominal obesity was defined as the WHtR of over $0.5[12,13]$.Community urbanicity was calculated by an urbanization index that comprises a 12-multicomponent (population density, economic activity, housing, education, diversity, modern markets, traditional markets, communications, transportation infrastructure, social services, sanitation, and health infrastructure) continuous scale ranging from 0 to 120 with higher values indicating higher levels of urbanicity for the sampled communities in each survey year $[19,20]$.

Since WC was not measured in the 1989 and 1991 surveys, our study used data from the seven CHNS conducted between 1993 and 2011, if height (in $\mathrm{cm}$ ) and WC (in $\mathrm{cm}$ ) information was collected. The final analytic data contained 23,243 individuals (65,359 observations) aged of 18 and or above at multiple exams (mean number of measurements: 3). We added gender (a dummy variable coded 100 for males and 0 for females), race/ ethnicity (100 for Han ethnicity and 0 for other minorities), marital status (100 for Married and 0 for others), community urbanicity, years of education and per capita net annual household income, as well as age and age-squared, into the mixed-effects models to identify socioeconomic disparities in prevalence of abdominal obesity over the adult life course [20].We chose to use mixed effects models because they are particularly useful in analyzing the relationship between the independent 
variables and the response variables for longitudinal settings with repeated measurements of the same statistical units $[10,20]$. In three mixed effects models (Additional file 1; model 1 , model 2 and model 3 ), we used a sample of 23,243 individuals (65,359 observations) aged 18 or above for analysis. Besides that, there were 1493 participants with measurements for all seven surveys. We used this sample of 1493 individuals to estimate the trajectories of probability of abdominal obesity prevalence across the adult life course by unadjusted mixed effects models stratified by baseline age group (birth cohort) [10]. Birth cohorts were stratified into 5 groups: Cohort 1931-1940, Cohort 1941-1950, Cohort 1951-1960, Cohort 1961-1970, and Cohort 19711980 (Additional file 1: Table S4).All statistical tests were conducted, using STATA version 12.

\section{Results}

Table 1 showed the basic information of the participants in the 1993-2011 CHNS. Curvilinear age effects on the prevalence of abdominal obesity were observed confirming non-linear increase with age [coefficient (95\% confidence intervals): $2.60(2.46,2.74)$ for age and -0.018 ($0.019,-0.017)$ for age-squared; all $P<0.001$ ] over the adult life course (Table 2, Model 1, Additional file 1: Table S1). After controlling for age, significant period effects on the prevalence of abdominal obesity were observed which were particularly substantial from 1993 to 2011 (Table 2, Model 1). Unadjusted linear mixed effects model stratified by birth cohort showed that prevalence of abdominal obesity was higher in the younger birth cohorts than in the older ones (Fig. 1,
Additional file 1: Table S4), and prevalence of abdominal obesity was higher in the 1941-1950, 1951-1960, 1961-1970 and 1971-1980 cohorts than that in the 19311940 cohort [coefficient (95\% confidence intervals): 8.328(4.011, 12.644), 15.500(10.851, 20.149), 20.740(15.254, 26.225) and 34.908(24.079, 45.737), respectively; all $P<$ 0.001]. And at any given age, prevalence of abdominal obesity increased for each successive cohort for both men and women (Fig. 1). For instance, at the age of 60, prevalence of abdominal obesity among men was higher in the 1941-1950 cohort than in the 1931-1940 cohort (about $30 \%$ vs $40 \%$ ), but lower than in the $1951-1960$ cohort (nearly 60\%).

Abdominal obesity was less prevalent among males than females [coefficient (95\% confidence intervals): 0.065(-0.075,-0.055); $P<0.001$ ] (Table 2, Model 1), and an interaction between survey year and gender was observed (Table 2, Model 2, Additional file 1: Table S2), which indicated that the period effect was stronger among males than females. Abdominal obesity was more prevalent among ethnic Han Chinese and the married [coefficient (95\% confidence intervals): $0.03(0.003,0.057)$ and $0.035(0.022,0.047)$, respectively; $P=0.03$ and $P<0.001$, respectively] (Table 2, Model 3, Additional file 1: Table S3). A higher-level urbanization and higher household income increased the probability of abdominal obesity [coefficient (95\% confidence intervals): $0.160(0.130,0.191)$ and $3.47 \mathrm{E}^{-4}\left(2.23 \mathrm{E}^{-4}, 4.70 \mathrm{E}^{-4}\right)$, respectively; all $\left.P<0.001\right]$, but individuals with a higher-level of education were less likely to develop abdominal obesity [coefficient (95\% confidence intervals): $-0.222(-0.289,--0.155) ; P<0.001]$ across adulthood (Table 2, Model 3).

Table 1 General characteristic of Chinese adult population from the 1993-2011 CHNS $^{\text {a }}$

\begin{tabular}{|c|c|c|c|c|c|c|c|}
\hline & \multicolumn{7}{|l|}{ Survey Year } \\
\hline & 1993 & 1997 & 2000 & 2004 & 2006 & 2009 & 2011 \\
\hline Participated & 7810 & 4498 & 5918 & 6408 & 6623 & 6319 & 7319 \\
\hline New participated & - & 3865 & 3421 & 2574 & 2239 & 3067 & 5298 \\
\hline With drowal /Died & - & 3312 & 2445 & 2931 & 2359 & 2543 & 2067 \\
\hline Age & $42.1(15.7)$ & $43.7(15.8)$ & $45.2(15.4)$ & $48.2(15.3)$ & $49.5(15.2)$ & $50.4(15.4)$ & $51.3(15.2)$ \\
\hline Gender $^{\mathrm{b}}$ & 47.4 & 48.5 & 47.7 & 47.5 & 46.9 & 47.3 & 46.7 \\
\hline Ethnicy ${ }^{c}$ & 95.4 & 94.5 & 95.1 & 95.2 & 95.7 & 95.7 & 97.2 \\
\hline Marital status $^{d}$ & 78.8 & 79.0 & 80.7 & 82.6 & 83.9 & 84.0 & 84.5 \\
\hline Education years & 15.9(9.7) & $16.4(9.5)$ & $17.5(9.2)$ & 18.8(8.8) & 18.8(9.4) & 19.1(9.0) & 20.6(8.9) \\
\hline Household income ${ }^{e}$ & $3481(3044)$ & 4197(3561) & $5626(5767)$ & $7473(7692)$ & 8838(11971) & $12,421(15667)$ & $15,521(16641)$ \\
\hline Community urbanicity $^{f}$ & $48.3(16.5)$ & $52.3(18.0)$ & $59.3(18.4)$ & $63.1(20.3)$ & $65.0(20.4)$ & $67.5(19.4)$ & 73.2(19.2) \\
\hline Abdominal obesity & 45.1 & 46.9 & 49.1 & 55.1 & 57.2 & 59.4 & 63.4 \\
\hline
\end{tabular}

${ }^{a}$ Values presented as numbers for arbitrary values and as mean \pm SD or $\%$ for other variables

${ }^{\mathrm{b}}$ Gender was a dummy variable coded 100 for males and 0 for females

${ }^{\mathrm{C} E t h n i c i t y / r a c e}$ was a dummy variable coded 100 for ethnic Han and 0 for other minorities

${ }^{d}$ Marital status was a dummy variable coded 100 for Married and 0 for others

eper capita net annual household income was calculated at the household level for each survey year and inflated to 2011

${ }^{\mathrm{f} C}$ Community urbanicity was measured at the community level on a 12-component continuous scale ranging from 0 to 120 with higher values corresponding to higher levels of urbanicity 
Table 2 Parameter estimates (95\% confidence intervals) from mixed effects models predicting of the probability of abdominal obesity over the adults life course

\begin{tabular}{|c|c|c|c|}
\hline & Model 1 & Model 2 & Model 3 \\
\hline Age & $2.60(2.46,2.74)$ & $1.82(1.49,2.14)$ & $1.508(1.132,1.885)$ \\
\hline $\mathrm{Age}^{2}$ & $-0.018(-0.019,-0.017)$ & $-0.011(-0.014,-0.007)$ & $-0.008(-0.012,-0.004)$ \\
\hline Gender $^{\mathrm{a}}$ & $-0.065(-0.075,-0.055)$ & $-0.105(-0.125,-0.086)$ & $-0.100(-0.121,-0.080)$ \\
\hline $1997^{\mathrm{b}}$ & $4.85(3.66,6.04)$ & $-6.98(-16.33,2.37)$ & $-7.67(-18.09,2.75)$ \\
\hline 2000 & $10.98(9.81,12.15)$ & $-17.78(-27.32,-8.24)$ & $-21.15(-32.14,-10.17)$ \\
\hline 2004 & $14.48(13.27,15.69)$ & $-15.53(-25.75,-5.30)$ & $-18.84(-29.88,-7.80)$ \\
\hline 2006 & $15.06(13.83,16.28)$ & $-11.98(-22.49,-1.47)$ & $-17.47(-28.84,-6.10)$ \\
\hline 2009 & $19.40(18.17,20.64)$ & $-9.94(-20.42,0.54)$ & $-13.17(-24.50,-1.84)$ \\
\hline 2011 & $22.49(21.29,23.70)$ & $-7.10(-17.16,2.95)$ & $-11.67(-22.60,-0.74)$ \\
\hline $1997^{*}$ Gender & & $0.027(0.004,0.051)$ & $0.030(0.005,0.056)$ \\
\hline $2000 *$ Gender & & $0.039(0.016,0.062)$ & $0.042(0.017,0.068)$ \\
\hline $2004^{*}$ Gender & & $0.036(0.012,0.060)$ & $0.049(0.024,0.074)$ \\
\hline $2006^{*}$ Gender & & $0.041(0.017,0.065)$ & $0.048(0.023,0.074)$ \\
\hline $2009 *$ Gender & & $0.044(0.020,0.068)$ & $0.052(0.027,0.077)$ \\
\hline $2011^{*}$ Gender & & $0.071(0.048,0.094)$ & $0.079(0.055,0.103)$ \\
\hline $1997^{*} \mathrm{Age}$ & & $0.519(0.100,0.938)$ & $0.497(0.033,0.961)$ \\
\hline $2000^{*}$ Age & & $1.21(0.787,1.631)$ & $1.317(0.838,1.795)$ \\
\hline $2004^{*}$ Age & & $1.257(0.815,1.698)$ & $1.318(0.841,1.795)$ \\
\hline $2006^{*}$ Age & & $1.046(0.598,1.494)$ & $1.200(0.715,1.685)$ \\
\hline $2009^{*} \mathrm{Age}$ & & $1.115(0.670,1.560)$ & $1.143(0.660,1.626)$ \\
\hline $2011^{*}$ Age & & $1.126(0.699,1.554)$ & $1.205(0.740,1.670)$ \\
\hline $1997^{*} \mathrm{Age}^{2}$ & & $-0.006(-0.010,-0.001)$ & $-0.005(-0.010,-0.0004)$ \\
\hline $2000^{*} \mathrm{Age}^{2}$ & & $-0.012(-0.016,-0.008)$ & $-0.013(-0.018,-0.008)$ \\
\hline $2004^{*} \mathrm{Age}^{2}$ & & $-0.012(-0.0170,-0.008)$ & $-0.013(-0.018,-0.006)$ \\
\hline $2006^{*} \mathrm{Age}^{2}$ & & $-0.010(-0.014,-0.005)$ & $-0.011(-0.016,-0.006)$ \\
\hline $2009^{*} \mathrm{Age}^{2}$ & & $-0.010(-0.015,-0.006)$ & $-0.011(-0.015,-0.006)$ \\
\hline $2011^{*} \mathrm{Age}^{2}$ & & $-0.011(-0.015,-0.006)$ & $-0.012(-0.016,-0.007)$ \\
\hline Ethnicy $^{c}$ & & & $0.030(0.003,0.057)$ \\
\hline Marital status ${ }^{d}$ & & & $0.035(0.022,0.047)$ \\
\hline Community urbanicity ${ }^{\mathrm{e}}$ & & & $0.160(0.130,0.191)$ \\
\hline Education years & & & $-0.222(-0.289,-0.155)$ \\
\hline Household income $^{f}$ & & & $3.47 \mathrm{E}^{-4}\left(2.23 \mathrm{E}^{-4}, 4.70 \mathrm{E}^{-4}\right)$ \\
\hline Community urbanicity*household income & & & $-4.67 \mathrm{E}^{-6}\left(-6.27 \mathrm{E}^{-6},-3.08 \mathrm{E}^{-6}\right)$ \\
\hline intercept & $-40.13(-43.41,-36.85)$ & $-20.26(-27.33,-13.19)$ & $-21.94(-30.45,-13.43)$ \\
\hline
\end{tabular}

${ }^{\mathrm{a}}$ Gender was a dummy variable coded 100 for males and 0 for females and with 0 as a reference category

bSurvey year was a dummy variable with 1993 as a reference category

'Ethnicity/race was a dummy variable coded 100 for ethnic Han and 0 for other minorities and with 0 as a reference category

${ }^{\mathrm{d}}$ Marital status was a dummy variable coded 100 for Married and 0 for others and with 0 as a reference category

${ }^{e}$ Community urbanicity was measured at the community level on a 12-component continuous scale ranging from 0 to 120 with higher values corresponding to

higher levels of urbanicity

fPer capita net annual household income was calculated at the household level for each survey year and inflated to 2011

\section{Discussion}

Our longitudinal analysis used data from the 1993-2011 CHNS. This series of surveys, stretching over 18 years, was based on a large nationally representative sample. To our knowledge, this is the first large-scale longitudinal study ever conducted in the whole country to systemically examine socioeconomic disparities in abdominal obesity over the adult life course. The findings showed that prevalence of abdominal obesity increased non-linearly with age over the adult life course. Also, prevalence of abdominal 

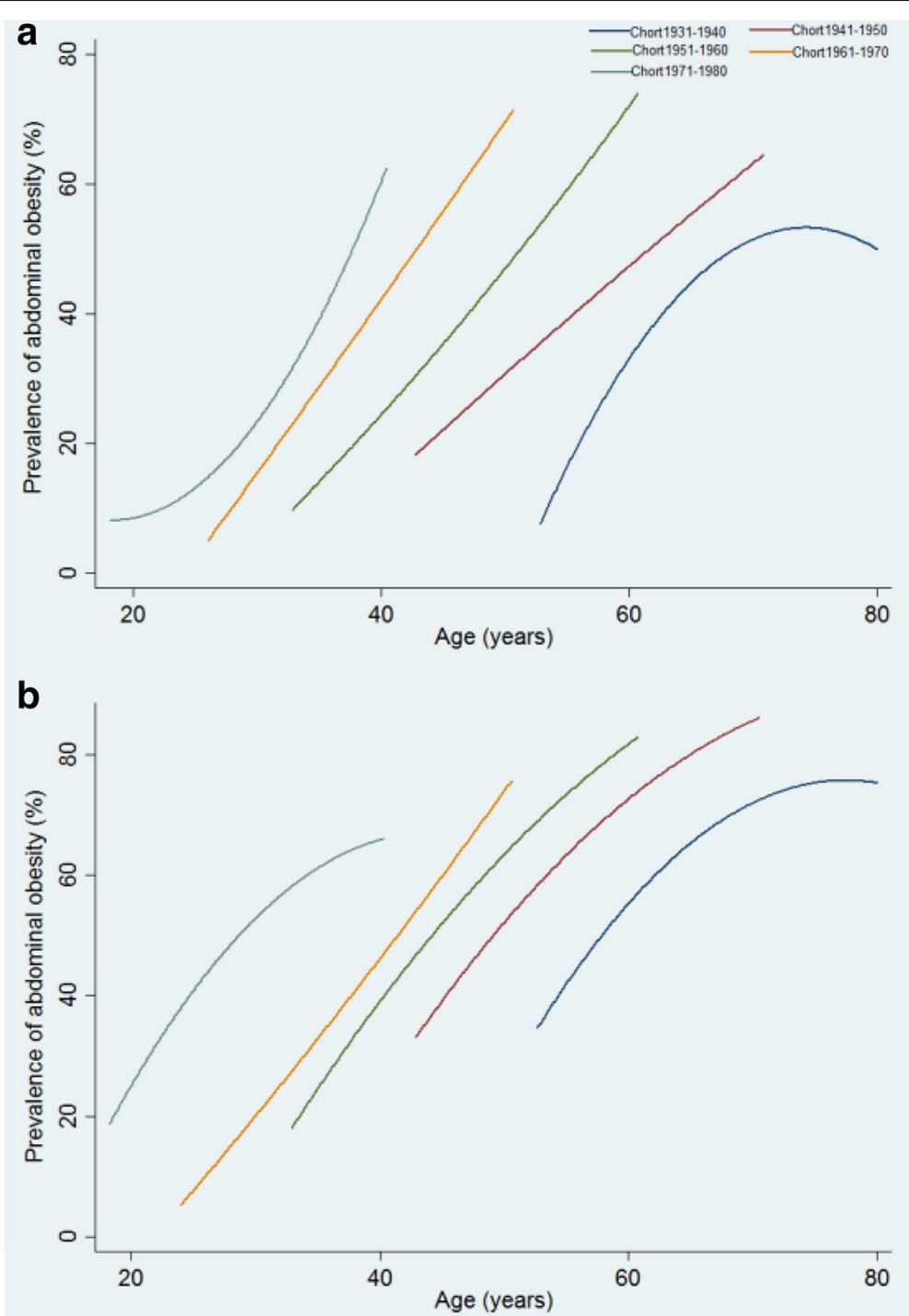

Fig. 1 Trajectories of the probability of abdominal obesity (\%) across the life course for 1493 participants with measurements for all 7 surveys among men (a) and women (b) adult, estimated by multilevel mixed effects models stratified by baseline age group (Birth cohort) (Birth cohorts were stratified into 5 groups: Cohort 1931-1940, Cohort 1941-1950, Cohort 1951-1960, Cohort 1961-1970, Cohort 1971-1980)

obesity substantially increased with period and cohort, especially for males. Furthermore, women, those of Han ethnicity, the married, and individuals with higher household income or a lower educational level or living in more urbanized communities were more likely to experience abdominal obesity over the adult life course.

No previous studies have examined cohort effects on abdominal obesity in China, and most cross-sectional studies fail to demonstrate a longitudinal trend of abdominal obesity. In longitudinal studies, cohort effects could illuminate the dynamics of abdominal obesity in younger generations [11]. In our longitudinal analyses, abdominal obesity was more prevalent in the younger birth cohorts than older cohorts. In the U.S., the National Health and Nutrition Examination Survey (NHANES) estimated that the Silent Generation (1924-1943) and Generation X (1964-1978) revealed positive cohort effects on abdominal obesity compared with the Baby Boomers (the 1959-1963 birth cohort) [11]. Baby Boomers in the U.S. appeared to experience lower cohort-specific risk of abdominal obesity than older or younger birth cohorts [11]. But abdominal obesity substantially increased with more recent cohorts in China. Compared to the 1931-1940 birth cohort in China, prevalence of abdominal obesity continuously increased and was higher in the 1941-1950, 1951-1960, 1961-1970 and 1971-1980 cohorts.

Consistent with the positive cohort effects, the longitudinal analysis found that prevalence of abdominal obesity also increased consistently during the survey years and age effect was obviously observed in this study. Another 
study [20] carried out using data from the 1991-2009 China Health and Nutrition Survey found that BMI increased with age and survey years. The two results confirmed that, in terms of age and period effects, the increase in abdominal obesity was matched by an increase in general obesity and WHtR was matched by an increase in BMI, to some extent. Increase in sedentary lifestyle [21, 22], as well as energy intake [23], may play a role in this rise of abdominal obesity. China has experienced rapid changes in physical activity and dietary habits during the past two decades [21-23]. For example, the dietary patterns have changed to high-energy and high-fat foods from predominantly rice and wheat [24]. And younger generations in China tend to have a more sedentary lifestyle [22] and tend to have more meat and dairy product, as well as food heavy with fat and sugar instead of grains, vegetables and fruits [23], which may raise prevalence of abdominal obesity in the younger birth cohorts. Increased prevalence of abdominal obesity among Chinese adults will likely bring higher morbidity and mortality from diabetes [2], metabolic syndrome and cardiovascular diseases $[3,4]$. All this implies an emerging and serious public health problem, if there are no effective interventions to prevent and control abdominal obesity.

In our study, prevalence of abdominal obesity was higher among females than males, but the period effect was stronger among men than women. In South Korea [25], U.S. [26], and Sweden [27], males also experienced greater increases in abdominal obesity than females. Some studies showed that increased usage of motor vehicles and associated rise of sedentary lifestyle might have a greater influence on males than females $[5,6]$, which may contribute to gender differences in abdominal obesity increase. Differences between Han Chinese and ethnic minorities in relation to risk factors, such as differences in dietary patterns [28], may explain lower prevalence of abdominal obesity among ethnic minorities relative to Han Chinese.

Our study showed that urbanization was related to higher prevalence of abdominal obesity, which was consistent with evidence from other developing countries $[5,29]$. Urbanization typically decreases levels of physical activity and increases availability of food, particularly fast foods [5]. A study has found that less open space and increased use of motorized transportation in urbanized communities were conducive to physical inactivity [30], which may help explain the increased risk of abdominal obesity among Chinese caught up in the process of urbanization. In this study, individuals with higher educational attainment were less likely to have abdominal obesity across adulthood. Studies in some developed [31] and developing countries [5, 32] have also shown that education was a "protective" factor in relation to obesity. It may be because people with higher education have greater access to and better understanding of information about nutrition, they are more likely to adopt healthier dietary habits and a better lifestyle $[6,8]$.

What needs to be noted here is that community urbanicity in this study had 12 components, one of which was education. Education as one component of the community urbanicity was related to the individual highest education years to a certain extent. Education as one component of the community urbanicity and the individual highest education years were likely to similarly impact the prevalence of abdominal obesity to a certain extent. But "education" as one component of the community urbanicity was defined as "average education level among adults $>21$ years old" [19] for the communities, while another "education years" meant the highest education years for individuals. Moreover, the other 11 components (population density, economic activity, housing, diversity, modern markets, traditional markets, communications, transportation infrastructure, social services, sanitation, and health infrastructure) of the community urbanicity [19] may also impact the prevalence of abdominal obesity. For example, transportation infrastructure, one component of community urbanicity, included most common type of road, distance to bus stop, and distance to train stop [19], which might be related to the use of motor vehicles and the rise of physical inactivity, and might further impact the epidemic of obesity in the population [5, 22]. These may be the reason for the results that education was a "protective" factor but community urbanicity was a "risk" factor in relation to abdominal obesity in this study.

In developed countries, age adjusted prevalence of abdominal obesity decreases with income $[5,6]$. By contrast, our analysis has found that individuals with higher household income are more likely to experience abdominal obesity. This difference could be due to different stages of social development between developing and developed countries. In high-income countries, the relationship between abdominal obesity and higher income may be attenuated by increased sensitivity about healthy behaviors among better-off individuals and having the financial resources to participate in weight loss efforts [6]. Epidemiological transitions were observed in some middle-income countries where higher epidemic among rich population was revered to in the poor population [5]. In China, household income was an important factor to affect dietary structure and nutrients intake [33]. The traditional Chinese dietary patterns (high carbohydrate, low fat and high dietary fiber) have shifted to greater consumption of meat and animal fat, particularly among wealthier individuals [33]. As the household income increases, Chinese residents' choices of food will be more abundant, and they may easily access high-fat and energy-dense foods [33].The increased intake of high-energy foods in wealthy 
residents may lead to weight gains and abdominal obesity. With the rapid increase of China residents' income, the adverse change of dietary structure may increase the risk of abdominal obesity, general obesity and chronic noncommunicable diseases [33].

The loss of follow-up data is the limitation in this study, and dietary pattern and physical activity are unavailable and not in our statistical analyses. Another limitation is that we were constrained by variables contained in the CHNS. Thus, the key socioeconomic factors we used in our analysis were: gender, ethnicity, marital status, urbanization, educational attainment and per capita net annual household income. As well, we only analyzed the interactions between survey year and gender, between survey year and age, between survey year and age-squared, and between urbanicity and household income. Maybe the collinearity of other variables needs to be taken into consideration in further studies.

\section{Conclusion}

The increasing prevalence of abdominal obesity in China in the past several decades is a function of changing lifestyle of the Chinese people in terms of work, physical activity and diet. Lifestyle changes, in turn, reflect the substantial social and economic transformation of contemporary China. If unchecked, the proportion of the Chinese population becoming overweight or obese will grow and this will become a major public health concern and a challenge to the health care system.

Past studies have amply documented the dire health consequences of obesity. Since the aforementioned social and economic trends in China will likely continue unabated, though perhaps at a less dizzying speed, efforts to halt or even reverse the growing trend of abdominal obesity among the Chinese population are urgently needed. These may include massive undertakings in health promotion and education, particularly concerning diets and physical activity; changes in public policies regarding the food industry, especially the fast food industry; proper labeling of fat, sugar and cholesterol contents in pre-packaged food; and imposing special taxes on "unhealthy" food, such as sugar-loaded soft drinks. Special interventions may also be necessary to target vulnerable populations, such as those we have identified in this study.

\section{Additional file}

Additional file 1: Mixed-effects models (models 1, 2, 3) with age, age-squared, gender, survey year, ethnicity, marital status, education years, community urbanization and per capita net annual household income taken into consideration. (DOCX $32 \mathrm{~kb}$ )

\section{Abbreviations}

BMI: Body mass index; CHNS: China Health and Nutrition Survey; WC: Waist circumference; WHtR: Waist-to-height ratio

\section{Acknowledgements}

This research uses data from China Health and Nutrition Survey (CHNS). We thank the National Institute for Nutrition and Health, China Center for Disease Control and Prevention, Carolina Population Center (P2C HD050924, T32 HD007168), the University of North Carolina at Chapel Hill, the NIH (R01HD30880, DK056350, R24 HD050924, and R01-HD38700) and the NIH Fogarty International Center (D43 TW009077, D43 TW007709) for financial support for the CHNS data collection and analysis files from 1989 to 2015 and future surveys, and the China-Japan Friendship Hospital, Ministry of Health for support for CHNS 2009, Chinese National Human Genome Center at Shanghai since 2009, and Beijing Municipal Center for Disease Prevention and Control since 2011. We acknowledge professor Raymond W Pong for reviewing the manuscript.

\section{Funding}

This work is supported by The Measurement of Health Inequalities of NCDs and Construction of the Mechanism Model of Its Impact Factors - Base on the Diderichsen Theory' from National Natural Science Fund of China (grant NO.71704083), Study on the Vertical Integration Strategies in Health Services for Rural Patients with Chronic Diseases Based on Comprehensive Incentive Model' from the National Natural Science Fund of China (grant NO.71473130), and the general project of social science research for Jiangsu university, education department of Jiangsu province (grant NO.2017SJB0272) and social science research for Nanjing Medical university (grant NO.2017ZSZ006). However, the funding agencies had no role in the design, conduct analysis, and interpretation of this article.

\section{Availability of data and materials}

The datasets generated and/or analysed during the current study are available in the this repository [http://www.cpc.unc.edu/projects/china/data/ data.html.]

\section{Authors' contributions}

PZ and XG contributed equally to this work. PZ and XG wrote the analysis plan and had the primary responsibility of writing this paper. FY and DQ supervised the research process and data analysis, reviewed and revised all drafts of this manuscript. All authors read and approved the final manuscript.

\section{Ethics approval and consent to participate}

Survey protocols, instruments and the process for obtaining informed consent for this study were approved by the institutional review committees of the University of North Carolina at Chapel Hill, the National Institute of Nutrition and Food Safety, Chinese Center for Disease Control and Prevention, and the China-Japan Friendship Hospital, Ministry of Health.

\section{Consent for publication}

Not applicable.

\section{Competing interests}

The authors declare that they have no competing interests.

\section{Publisher's Note}

Springer Nature remains neutral with regard to jurisdictional claims in published maps and institutional affiliations.

Received: 24 November 2017 Accepted: 22 June 2018

Published online: 05 July 2018

\section{References}

1. Lu J, Bi Y, Ning G. Curbing the obesity epidemic in China. Lancet Diabetes Endocrinol. 2016;4(6):470-1.

2. Dong J, Ni YQ, Chu X, Liu YQ, Liu GX, Zhao J, Yang YB, Yan YX. Adipose tissue distribution is associated with glycaemic control and microalbuminuria in Chinese patients with type 2 diabetes: a cross-sectional study. Public Health. 2016;131:3-10. https://doi.org/10.1016/j.puhe.2015.08.001. Epub 2015 Nov 11

3. Schneider HJ, Friedrich N, Klotsche J, Pieper L, Nauck M, John U, Dörr M, Felix S, Lehnert H, Pittrow D, Silber S, Völzke H, Stalla GK, Wallaschofski H, Wittchen $\mathrm{HU}$. The predictive value of different measures of obesity for incident cardiovascular events and mortality. J Clin Endocrinol Metab. 2010; 95(4):1777-85. 
4. Zhang C, Rexrode KM, van Dam RM, Li TY, Hu FB. Abdominal obesity and the risk of all-cause, cardiovascular, and cancer mortality: sixteen years of follow-up in US women. Circulation. 2008;117(13):1658-67.

5. Musaiger AO. Overweight and Obesity in Eastern Mediterranean Region: Prevalence and Possible Causes. J Obes. 2011;407237 https://doi.org/10. $1155 / 2011 / 407237$

6. Yoo S, Cho H-J, Khang Y-H. General and abdominal obesity in South Korea, 1998-2007: Gender and socioeconomic differences. Prev Med. 2010;51:460-5.

7. Cai L, He J, Song Y, Zhao K, Cui W. Association of obesity with socioeconomic factors and obesity-related chronic diseases in rural Southwest China. Public Health. 2013;127(3):247-51.

8. Wang H, Wang J, Liu M-M, Da Wang Y-QL, Zhao Y, Huang M-M, Liu Y, Sun J, Dong G-H. Epidemiology of general obesity, abdominal obesity and related risk factors in urban adults from 33 communities of northeast china: the CHPSNE study. BMC Public Health. 2012:12:967. http://www.biomedcentral. com/1471-2458/12/967

9. Hulmán A, Tabák AG, Nyári TA, Vistisen D, Kivimäki M, Brunner EJ, Witte DR. Effect of secular trends on age-related trajectories of cardiovascular risk factors: the Whitehall II longitudinal study 1985-2009. Int J Epidemiol. 2014: 866-77. https://doi.org/10.1093/ije/dyt279.

10. Yang F, Qian D, Liu X. Socioeconomic disparities in prevalence, awareness, treatment, and control of hypertension over the life course in China. Int J Equity Health. 2017;16:100. https://doi.org/10.1186/s12939-017-0597-8.

11. Robinson WR, Utz RL, Keyes KM, Martin CL, Yang Y. Birth cohort effects on abdominal obesity in the United States: the silent generation, baby boomers, and generation X. Int J Obes. 2013;37(8):1129-34. https://doi.org/ 10.1038/ijo.2012.198

12. Zeng Q, He Y, Dong S, Zhao X, Chen Z, Song Z, Chang G, Yang F, Wang Y. Optimal cut-off values of BMl, waist circumference and waist: height ratio for defining obesity in Chinese adults. Br J Nutr. 2014;112(10):1735.

13. Browning LM, Hsieh SD, Ashwell M. A systematic review of waist-to-height ratio as a screening tool for the prediction of cardiovascular disease and diabetes: 0.5 could be a suitable global boundary value. Nutr Res Rev. 2010; 23(2):247-69.

14. Ashwell M, Gunn P, Gibson S. Waist-to-height ratio is a better screening too than waist circumference and BMI for adult cardiometabolic risk factors: systematic review and meta-analysis. Obes Rev. 2012;13(3):275-86. https:// doi.org/10.1111/j.1467-789X.2011.00952.x. Epub 2011 Nov 23

15. Yuxia M. The impact of socioeconomic status and dietary-related factors on blood pressure among adults in 9 provinces of China (1991-2009). Beijing: China Center for Disease Control and Prevention; 2013.

16. China Health and Nutrition Survey. China Health and Nutrition Survey. 2013; Retrieved from http://www.cpc.unc.edu/projects/china.

17. Popkin BM, Du S, Zhai F, Zhang B. Cohort profile: the China health and nutrition survey-monitoring and understanding socio-economic and health change in China, 1989-2011. Int J Epidemiol. 2010;39(6):1435-40.

18. Tuan NT, Adair LS, Stevens J, Popkin BM. Prediction of hypertension by different anthropometric indices in adults: the change in estimate approach. Public Health Nutr. 2010;13(5):639-46.

19. Jones-Smith JC, Popkin BM. Understanding community context and adult health changes in China: development of an urbanicity scale. Soc Sci Med. 2010;71:1436-46.

20. Jaacks LM, Gordon-Larsen P, Mayer-Davis EJ, Adair LS, Popkin B. Age, period and cohort effects on adult body mass index and overweight from 1991 to 2009 in China: the China health and nutrition survey. Int J Epidemiol. 2013; 42:828-37.

21. Monda KL, Adair LS, Zhai F, Popkin BM. Longitudinal relationships between occupational and domestic physical activity patterns and body weight in China. Eur J Clin Nutr. 2008;62:1318-25.

22. Ng SW, Howard A-G, Wang HJ, Su C, Zhang B. The physical activity transition among adults in China: 1991-2011. Obes Rev. 2014;15(suppl.1):27-36.

23. Adair LS, Gordon-Larsen P, Du SF, Zhang B, Popkin BM. The emergence of cardiometabolic disease risk in Chinese children and adults: consequences of changes in diet, physical activity and obesity. Obes Rev. 2014;15(Suppl.1):49-59.

24. Xi B, Liang Y, He T, Reilly KH, Hu Y, Wang Q, Yan Y, Mi J. Secular trends in the prevalence of general and abdominal obesity among Chinese adults, 1993-2009. Obes Rev. 2012;13:287-96.

25. Khang YH, Yun SC. Trends in general and abdominal obesity among Korean adults: findings from 1998, 2001, 2005, and 2007 Korea National Health and nutrition examination surveys. J Korean Med Sci. 2010;25:1582-8.
26. Ford ES, Li C, Zhao G, Tsai J. Trends in obesity and abdominal obesity among adults in the United States from 1999-2008. Int J Obes. 2011:35:736-43.

27. Lilja M, Eliasson M, Stegmayr B, Olsson T, Söderberg S. Trends in obesity and its distribution: data from the northern Sweden MONICA survey, 1986-2004. Obesity (Silver Spring). 2008;16:1120-8.

28. Ruixing $Y$, Weixiong $L$, Hanjun $Y$, Dezhai $Y$, Shuquan $L$, Shangling $P$, Qiming F, Jinzhen W, Jianting G, Yaju D. Diet, lifestyle, and blood pressure of the middle-aged and elderly in the Guangxi Bai Ku Yao and Han populations. Am J Hypertens. 2008, 21(4):382-7. https://doi.org/10. 1038/ajh.2008.1. Epub 2008 Feb 7

29. Pradeepa R, Anjana RM, Joshi SR, Bhansali A, Deepa M, Joshi PP, Dhandania VK, Madhu SV, Rao PV, Geetha L, Subashini R, Unnikrishnan R, Shukla DK, Kaur T, Mohan V, Das AK. ICMR-INDIAB collaborative study group. Prevalence of generalized \& abdominal obesity in urban \& rural India- the ICMR - INDIAB study (phase-I) [ICMR - INDIAB-3]. Indian J Med Res. 2015; 142(2):139-50.

30. Alam DS, Talukder SH, Chowdhury MA, Siddiquee AT, Ahmed S, Pervin S, Khan S, Hasan K, Koehlmoos TL, Niessen LW. Overweight and abdominal obesity as determinants of undiagnosed diabetes and pre-diabetes in Bangladesh. BMC Obes. 2016;3(1):1-12.

31. López-Sobaler AM, Rodríguez-Rodríguez E, Aranceta-Bartrina J, Gil Á, González-Gross M, Serra-Majem L, Varela-Moreiras G, Ortega RM. General and abdominal obesity is related to physical activity, smoking and sleeping Behaviours and mediated by the educational level: findings from the ANIBES study in Spain. PLoS One. 2016;11(12):e0169027.

32. Monteiro CA, Conde WL, Popkin BM. Independent effects of income and education on the risk of obesity in the Brazilian adult population. J Nutr. 2001;131(3):881S.

33. Wang Z, Zhai F, He Y, Wang H. Influence of family income on dietary nutrients intake and dietary structure in China. J Hygiene Res. 2008;37(1):62.

Ready to submit your research? Choose BMC and benefit from

- fast, convenient online submission

- thorough peer review by experienced researchers in your field

- rapid publication on acceptance

- support for research data, including large and complex data types

- gold Open Access which fosters wider collaboration and increased citations

- maximum visibility for your research: over $100 \mathrm{M}$ website views per year

At BMC, research is always in progress.

Learn more biomedcentral.com/submissions 